\title{
Federal parties target home care
}

$\mathrm{A}$ slew of campaign promises on home care suggest that major changes in Canadian policies and programs are in the offing but some experts warn that what has actually been promised is either altogether meager or somewhat lacking in detail.

The home care promises include a Conservative Party proposal to increase nonrefundable tax credits for family caregivers; a Liberal Party vow to provide financial relief for family caregivers through employment insurance and tax benefits; and a New Democrat promise to enshrine home care as a medically necessary service under the Canada Health Act.

Improving long-term, home-based care for the infirmed or disabled is of growing concern to Canadians, says Dr. Jeffrey Turnbull, president of the Canadian Medical Association. As Canada's population continues to age, the demand for health care services in the home will only increase. If that demand isn't met, people who could have received care at home will instead end up in costly acute care settings, creating an incredible financial strain on the health care system.

Though the campaign promises are good first steps, says Turnbull, they are still rather piecemeal, focusing on particular pockets of care when so much more is needed to ensure high-quality, long-term home care for disabled or infirmed Canadians.

"We need more than just a simple intervention in one area," says Turnbull. "We need to bring all the different facets of care together, and bring them to the home."

For the Conservatives, that one simple intervention is tax relief for family caregivers. In its Mar. 22 budget, the federal government announced a nonrefundable tax credit of \$2000 for Canadians providing care to infirmed or dependent relatives.

Essentially, those caring for loved ones meeting certain criteria will get a tax credit of $\$ 2000$. But as with exist-

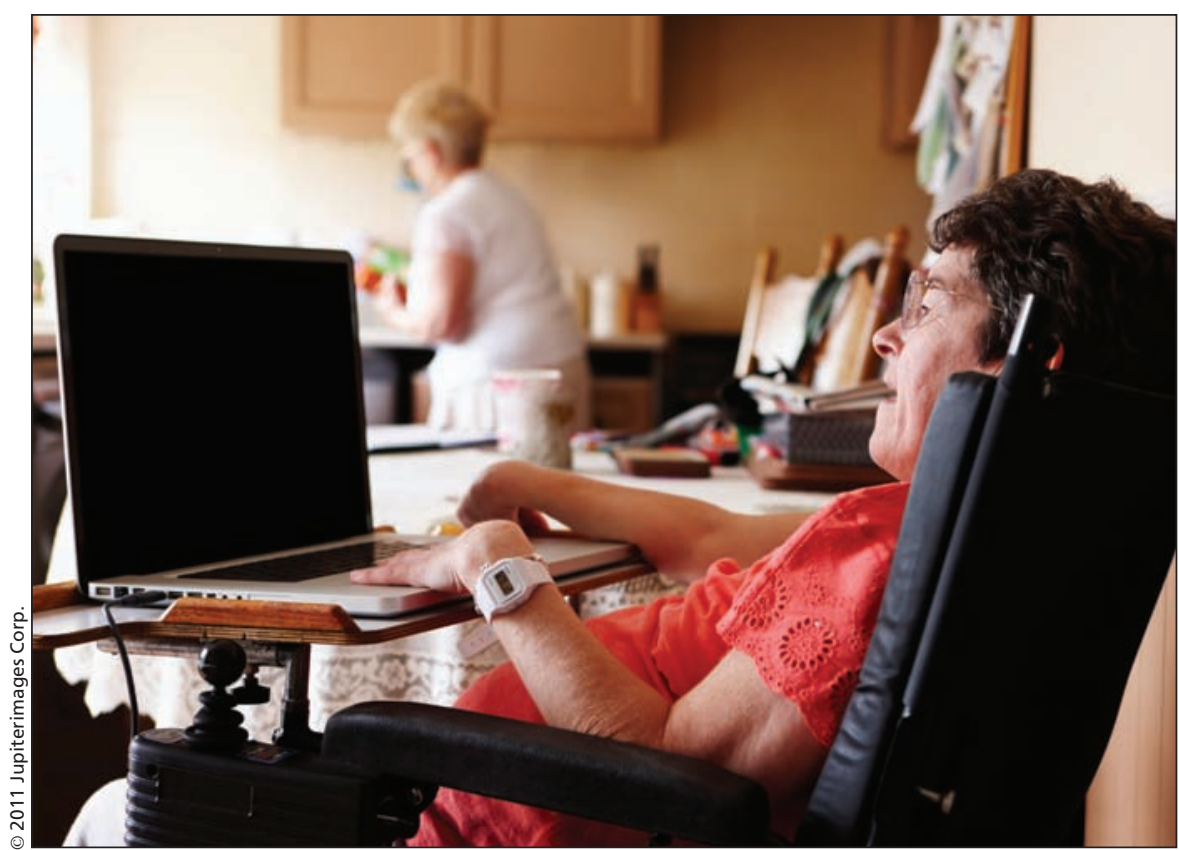

Among home care promises made on the campaign trail is one from the New Democrats that would enshrine home care as a medically necessary service under the Canada Health Act.

ing health-related tax support, it will be reduced by $15 \%$ for every dollar earned by the person receiving care. For example, someone providing care to an elderly parent is now eligible for $\$ 4385$ in existing tax support. The new caregiver tax credit bumps that up to $\$ 6385$. But if the parent has a pension, the total will be reduced by $15 \%$ of whatever monies the parent received or earned, with the aggregated tax credit and benefits disappearing entirely once the parent's income tops \$21360.

The credit will be added to existing health-related tax supports: the spousal or common-law partner credit (\$10 780), the child tax credit (\$2182), the eligible dependent credit (\$10 780), the caregiver credit $(\$ 4385)$ and the infirm dependent credit (\$4385).

The Conservatives laud the proposal as a major advance for seniors.

"Stephen Harper's Government has delivered more for seniors than any other Government in Canadian history," Chisholm Pothier, a spokesperson for Finance Minister Jim Flaherty, writes in an email. "The Stephen Harper Conservative government is introducing a new family caregiver tax credit because we respect and want to support the sacrifices that many Canadians make to care for family members with infirmities - often while caring for other family members and holding down a job. Providing additional tax relief to caregivers recognizes the additional expenses incurred when caring for a loved one who is infirm."

The Liberal Party, meanwhile, says that if elected, it will introduce what it calls a "family care plan," which also puts an emphasis on home care.

"Often the best place to provide care for our loved ones is in the home, with support provided by a family member or health care worker. This not only allows those who are in need of continuing care to receive support in their own homes, but also relieves the pressure those with continuing care needs can place on our front line health workers," Kate Purchase, campaign spokesperson for the Liberal Party of Canada, writes in an email. 
The \$1-billion family care plan has two parts. One is a program that would allow family caregivers to receive employment insurance benefits for up to six months, a significant increase over the six weeks now allowed. The second part is a family care tax benefit, worth up to $\$ 1350$ a year, that the Liberals say will provide financial relief to low- and middle-income family caregivers.

"Our Liberal Family Care Plan is a first step. In the long-term, we need a national commitment to home care, as envisioned in the 2004 health accord, but abandoned in early 2006," writes Purchase. "We need to restore our ambition - to support families and sustain our health care system. Our plan is in stark contrast to the Harper position that you simply should take vacation leave to look after your ill family."

But what's missing from both the Conservative and Liberal plans is support for professional health care services, says Marg McAlister, project manager for the Canadian Home Care Association. Though family caregivers play an important role in caring for infirmed and disabled relatives, a comprehensive approach to home care would also include more provisions for paid services, such as nursing, speech therapy and social work.

Still, McAlister is pleased that the topics of family caregivers and home care are at least being discussed. "What we are delighted about is that family care-giving and home care is being talked about," says McAlister, noting that although the Conservatives have been mostly silent on an overall home care plan, the NDP and Liberals have both at least mentioned a national home care program. "We are very optimistic that through this discussion and awareness, we are going to see some good policy emerge."

Without question, the most far reaching of the home care promises made on the campaign trail come from the New Democrats, as they vow to enshrine both home care and long-term care as medically necessary services under the Canada Health Act, and then propose a funding mechanism to pay for the cost of providing such services, specifically, a dedicated federal transfer payment to the provinces.

The New Democrats also say they'd spend $\$ 537$ million in their first year in office on a "Quality Home Care Plan" and a "Long-Term Care Initiative" that would allow 100000 more families to access home care and create 5000 new long-term care spaces. In addition, the party would spend $\$ 37$ million to help families modify their homes so that elderly can remain out of facilities for longer "by doubling the forgivable loan available under the existing Home Adaptations for Seniors' Independence (HASI) program - from $\$ 3,500$ to $\$ 7,000$. This program would provide assistance to up to 10,570 individuals and families per year."

Yet experts say that improved access to services and more financing aren't all that's needed.

Politicians must also do more to educate senior citizens, who will be needing home care services in rapidly increasing numbers, on how to plan for their "care years," Patty Randall, author of Let's Talk - The Care-Years: Taking Care of Our Parents/Planning for Ourselves, writes in an email.

Randall adds that if she could ask the leaders of the federal parties one question, it would be: "What is your party planning as a national (educational, awareness, incentive, advertising-type) program to help Canadian families understand what has changed, what is now involved in having a long-life span and what it will take so we may live successfully, independently and with choices right into our old-old years?"

People are living longer than ever before, Randall notes, and some families now have two generations of seniors living at the same time. Elder care is replacing child care as the "costly workplace problem for businesses and entrepeneurs."

People need to start saving more money for the services they will need in their "care years," and Canada's political leaders need to address that problem, adds Randall, who writes: "I want my elected leaders to develop and fund a 'national program' that is strategic, functional, positive and solutionoriented, one that will encourage, motivate and educate us as to what we need to do to 'age successfully' in 'today's Canada' - because we want to look forward to fruitful lifestyles 'right into and through our old-old years' which according to research may now well include our 110th+ birthdays." Roger Collier, CMAJ

CMAJ 2011. DOI:10.1503/cmaj.109-3856 